\title{
Simulated Electrification of a Small Thunderstorm with Two-Moment Bulk Microphysics
}

\author{
EDWARD R. MANSELL * \\ NOAA/OAR/National SEvere Storms Laboratory (NSSL) \\ Norman, OKlahoma, U.S.A. \\ Conrad L. Ziegler \\ NOAA/OAR/National Severe Storms Laboratory (NSSL) \\ Norman, OKLahoma, U.S.A. \\ ERIC C. BRUning \\ Cooperative Institute for Climate Studies, \\ Earth System Science Interdisciplinary Center, \\ University of Maryland, College Park, College Park, Maryland
}

\section{ABSTRACT}

\begin{abstract}
Electrification and lightning are simulated for a small continental multicell storm. The results are consistent with observations and thus provide additional understanding of the charging processes and evolution of this storm. The first six observed lightning flashes, all negative cloud-to-ground (CG) flashes, indicated at least an inverted dipole charge structure (negative charge above positive). Negative CG flashes should be energetically favorable only when the negative charge region contains appreciably more charge than the lower positive region. The simulations support the hypothesis that the negative charge is enhanced by noninductive charge separation higher in the storm that also causes development of an upper positive charge region, resulting in a "bottom-heavy" tripole charge structure.

The two-moment microphysics scheme used for this study can predict mass mixing ratio and number concentration of cloud droplets, rain, ice crystals, snow, graupel, and hail. (Hail was not needed for the present study.) Essential details of the scheme are presented. Bulk particle density of graupel and hail can also be predicted, which increases diversity in fall speeds. The prediction of hydrometeor number concentration is critical for effective charge separation at higher temperatures $(-5<T<-15)$ in the mixed-phase region, where ice crystals are produced by rime fracturing (Hallett-Mossop process) and by splintering of freezing drops.
\end{abstract}

\section{Introduction}

A small multicell storm complex was observed on 2829 June 2004 during the Thunderstorm Electrification and Lightning Experiment (TELEX) (MacGorman et al. 2008). The storm was located $50 \mathrm{~km}$ northwest of Norman, OK and remained stationary. Observation platforms included the KOUN polarimetric radar, a lightning mapping array (LMA), mobile radars, and soundings with electric field meters. The convection on this day was characterized by short-lived shallow cells, a few of which grew sufficiently above the freezing level to electrify strongly and produce lightning. Analysis of polarimetric radar by Bruning et al. (2007) indicated that the warm rain (collision-coalescence) process was likely the dominant mode of initial precipi- tation formation, and that graupel first appeared in the lightning-producing cells from freezing drops. Inference from LMA-observed lightning showed an initial significant charge structure composed of main negative and lower positive charges (negative dipole) with associated negative cloud-to-ground (CG) lightning. Subsequent upper-level intracloud (IC) lightning indicated development of a significant upper positive charge region. A negative screening layer at cloud top was inferred from electric field meter data but apparently was not involved in lightning.

The interpretation of the observations painted a reasonable picture of the lightning and microphysics of the storm, but some aspects remained unclear, particularly the initial charge structure of the storm that produced exclusively negative cloud-to-ground $(-\mathrm{CG})$ lightning flashes. 


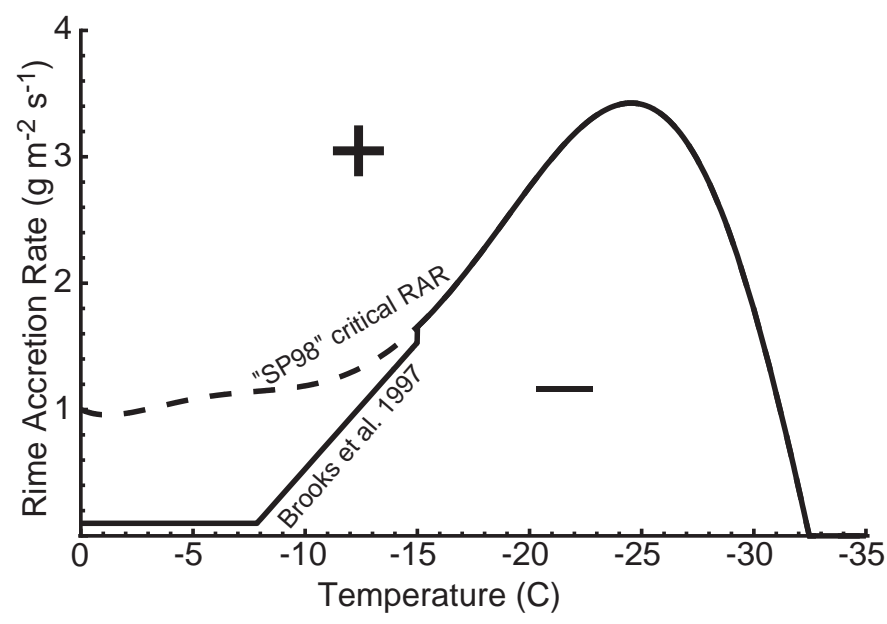

FIG. 1. Noninductive charge separation sign-reversal curve used in the present study. The critical rime accretion rate (RAR) curve follows Saunders and Peck (1998) for $T<$ $-15^{\circ} \mathrm{C}$ (shown as dashed curve for $T \geq-15^{\circ} \mathrm{C}$ ) and Brooks et al. (1997) at higher temperatures. Charge transfer is set to zero for $T<-33^{\circ} \mathrm{C}$.

The marginal flash rates and relatively low echo tops make for an interesting and challenging case for numerical modeling, both to evaluate microphysical and electrical processes and to gain further understanding of the observations.

\section{Model Details}

Electrification physics have been merged into a new version of the Collaborative Model for Multiscale Atmospheric Simulation (COMMAS) (Wicker and Wilhelmson 1995). As described in Coniglio et al. (2006), the model uses the basic equation set from Klemp and Wilhelmson (1978) and prognostic equations are included for momentum, pressure, potential temperature, and turbulent kinetic energy (Deardorff 1980). Time integration is performed with a thirdorder Runge-Kutta (RK) scheme (Wicker and Skamarock 2002). Advection on the first two RK iterations uses 5thorder upwind differencing. On the final RK step, scalar quantities (e.g., potential temperature, mixing ratio, number concentration, electric charge, etc.) are advected using a sixth-order finite difference with a monotonicity filter (Leonard 1991) and are computationally diffused (horizontal directions only) with the simple monotonic filter of Xue (2000), following Bryan (2005). Wind components, on the other hand, are advected with a 5th-order weighted essentially non-oscillatory (WENO) scheme (Jiang and Shu 1996; Shu 2003; Bryan 2005). Sedimentation uses the Kato (1995) first-order "box-Lagrangian" scheme.

The ice microphysics is an updated version of the scheme originally developed by Ziegler (1985) that predicts mass and number concentration for six hydrometeor types

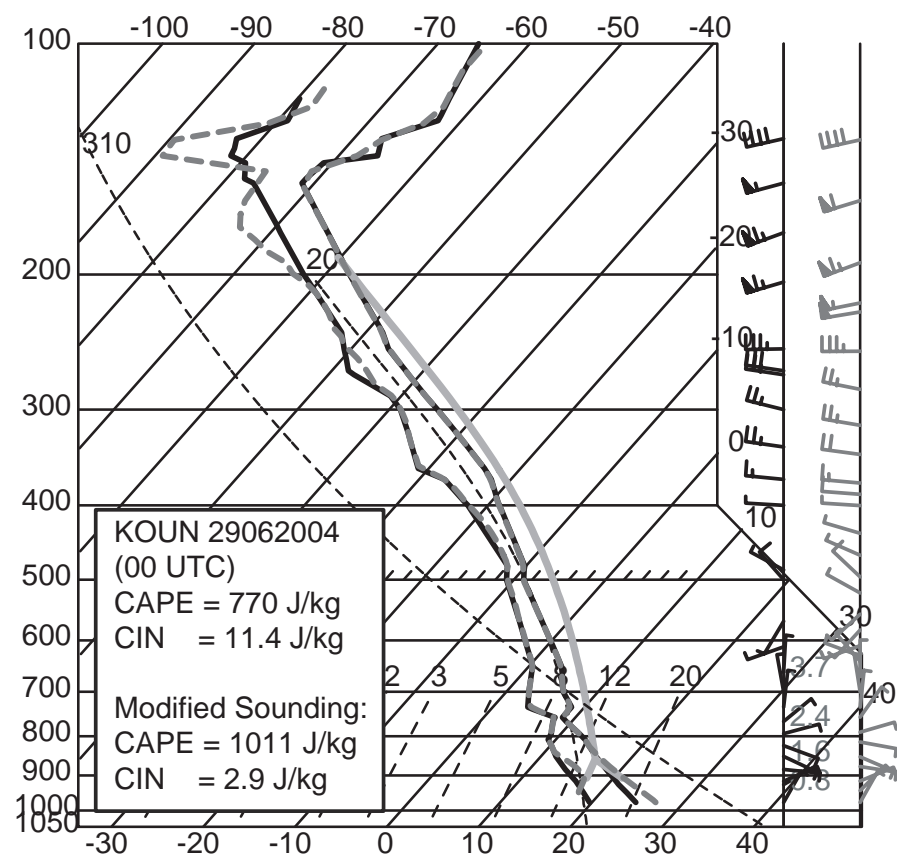

FIG. 2. Environmental sounding (solid curves) and model initialization sounding (dashed gray curves)

(droplets, rain, ice crystals, snow, graupel, and hail) and used in previous electrification studies with a kinematic model (Ziegler et al. 1986, 1991; Ziegler and MacGorman 1994). Details of the scheme are provided in the appendix. The two-moment scheme also predicts a bulk concentration of cloud condensation nuclei and predicts average bulk density of graupel and hail. There were no indications of large hail in this case, so the hail category was omitted to save computational cost. The variable density of graupel allows the single category to simulate a spectrum of particles, from high-density frozen drops (or small hail) to low-density graupel.

Electrification processes (Mansell et al. 2005) include parameterizations of multiple laboratory results of noninductive charge separation in rebounding graupel-ice collisions. Small ion processes such as attachment and drift motion are treated explicitly. A set of sensitivity tests found that of the standard noninductive charge separation schemes described by Mansell et al. (2005), the schemes based on rime accretion rate (e.g., Saunders and Peck 1998) worked better than the others to reproduce the charge and lightning development from lower dipole to full tripole that was inferred from LMA observations. Better results were achieved when no negative charge to graupel was allowed at higher temperatures $\left(T>-7.5^{\circ} \mathrm{C}\right)$. A hybrid scheme (Fig. 1) was developed that merged the parameterization of Brooks et al. (1997) for temperature $T>-15^{\circ} \mathrm{C}$ with Saunders and Peck (1998) for $T<-15^{\circ} \mathrm{C}$. Graupel collection efficiency for cloud droplets was set to a constant 


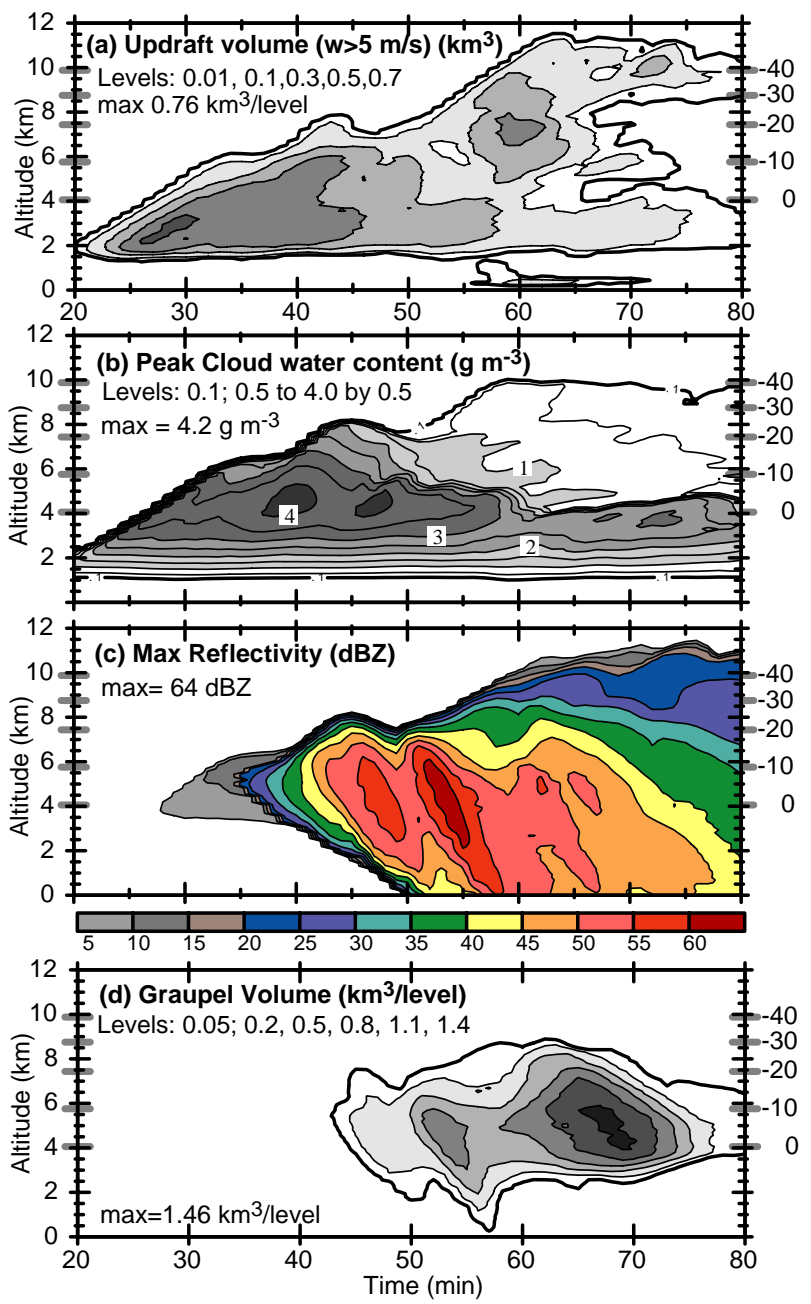

FIG. 3. Time-height quantities: (a) Updraft volume per model level, (b) maximum cloud water content, (c) maximum reflectivity, and (d) graupel volume per model level. Labels on the right-hand axis indicate environmental air temperature (also denoted by gray ticks on both axes).

$E_{g, w}=0.5$ for this study (Saunders et al. 1991). As in our previous studies, the effects of electric forces on dynamics are neglected .

The branched lightning parameterization of Mansell et al. (2002) was used, with charge neutrality of the channel structure now maintained by adjusting the electric potential of the channel (e.g., Mazur and Ruhnke 1998). A very similar scheme was recently employed by Riousset et al. (2007) with an idealized time-dependent charge configuration (i.e., not in a microphysical storm model). In Mansell et al. (2002), a simple height threshold (here $500 \mathrm{~m}$, or 4 grid points above ground) was used to declare a flash to be a CG (i.e., the flash was not required to propagate all the way to ground). In the updated scheme, the potential at the tip must maintain the correct sign to be connected
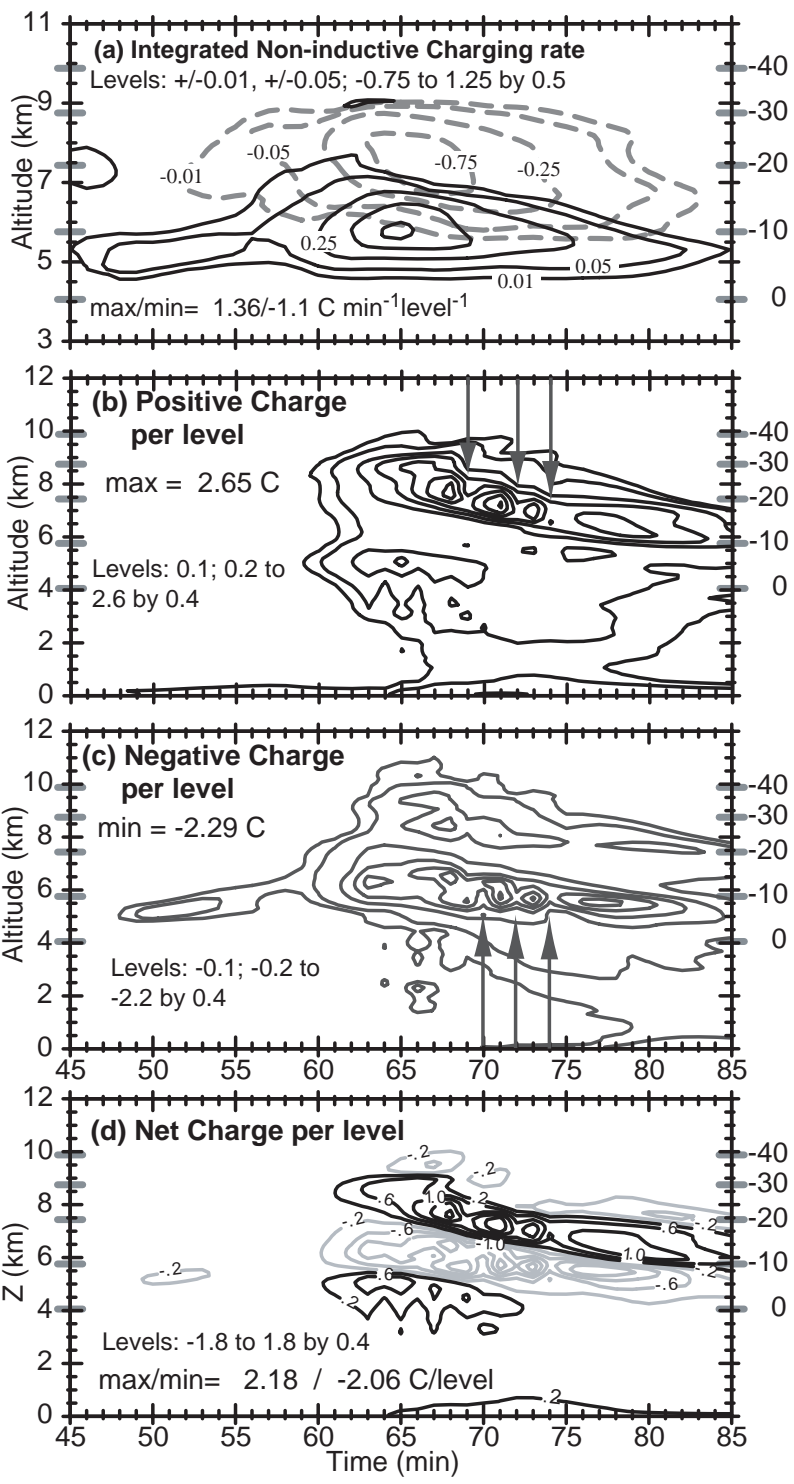

FIG. 4. (a) Noninductive charge separation rates, integrated by model level, between graupel and ice crystals/snow. Polarity indicates the sign of charge gained by graupel. (b) Layer total positive charge. (c) Layer total negative charge. (d) Layer net charge. Arrows in (b) and (c) indicate lightning events with obvious effects on the layer charge. 
to ground, since the sign can change due to internal resistance and adjustment of the channel potential. (Resistance is represented by an internal electric field, which in this study is set to $100 \mathrm{~V} \mathrm{~m}^{-1}$.) Another new feature is that the channel potentials are set to zero in the event of a $\mathrm{CG}$ flash, and further growth is allowed until the breakdown quenches itself.

Lightning is now initiated using the higher threshold runaway air breakdown determined by Dwyer (2003) and scaled from standard air density as $E_{\text {init }}=2.84 \times$ $10^{5}\left(\rho_{\text {air }} / \rho_{o}\right) \mathrm{Vm}^{-1}$. The model presently does not take into account the depth over which electric fields exceed $E_{\text {init }}$ (Dwyer 2003). The critical threshold electric field for channel propagation is still assumed to be some fraction of the initiation threshold, $E_{\text {crit }}(z)=f_{\text {crit }} E_{\text {init }}(z)$. To maintain similar lightning extents as the older, lower $E_{\text {init }}$, the present study uses $f_{\text {crit }}=0.43$.

As described in Mansell et al. (2005), a "potential domain" is used for solving the Poisson equation that extends laterally and vertically beyond the dynamics domain. The boundary conditions remain the same except at the top of the domain, where we now use a Dirichlet condiction of $\phi=\phi_{z, \mathrm{FW}}$. The average fair weather electric potential $\phi_{z, \mathrm{FW}}$ is found by numerical integration of the fair weather electric field (Gish 1944; Helsdon and Farley 1987)

\section{Initialization}

The horizontally-homogeneous model environment was initialized from a 00 UTC 29 June National Weather Service operational sounding (Fig. 2) launched from Norman, OK (USA). Tests with the unmodified sounding resulted in convection that decayed too rapidly after updraft forcing was removed (see below). Surface mesonet stations closer to the storm suggested locally higher surface temperatures, so the sounding was modified accordingly. The boundary layer moisture profile was adjusted to maintain slight stability in $\theta_{\mathrm{V}}$ (virtual potential temperature). These changes reduced convective inhibition (CIN) from 11.4 to $2.9 \mathrm{~J} \mathrm{~kg}^{-1}$ and increased CAPE from about 770 to $1011 \mathrm{~J} \mathrm{~kg}^{-1}$, resulting in longer-lived simulated storms. Simulations were performed in a $30-\mathrm{km}$ by $30-\mathrm{km}$ by $16-\mathrm{km}$ domain with constant spacing of $250 \mathrm{~m}$ in the horizontal and $125 \mathrm{~m}$ in the vertical from the surface to $10 \mathrm{~km}$, above which the spacing was stretched to a maximum of $500 \mathrm{~m}$. For lightning, charge was interpolated to a $125 \mathrm{~m}$ horizontal grid spacing.

Convection was initiated by an updraft forcing (acceleration) term that was applied for the first 30 minutes of simulation. The forcing term had a maximum amplitude of $1.75 \times 10^{-2} \mathrm{~m} \mathrm{~s}^{-2}$ and was applied in a spheroidal region in the center of the domain (horizontal radii of $8 \mathrm{~km}$ and vertical radius of $1 \mathrm{~km}$, vertically centered at $1 \mathrm{~km}$ ), dropping smoothly to zero as the square of the cosine function (as is typical for thermal bubble perturbations). The forced acceleration turns off where downward vertical motions exceed $0.1 \mathrm{~ms}^{-1}$ to allow downdrafts to exist in the forcing region (e.g., allowing horizontal roll circulations to form). Randomized thermal perturbations (maximum magnitude of $0.1 \mathrm{~K}$ ) were applied in a larger region to simulate natural fluctuations. The model domain was translated roughly southwestward, with a motion vector of $(-1.4,-0.5) \mathrm{m} \mathrm{s}^{-1}$

Considering the observational inference that the warmrain process was very active in this case, large cloud droplets were assumed, so simulation tests were performed to determine an appropriate $\mathrm{CCN}$ concentration. The model initiation of CCN concentration assumes that CCN are well mixed in the environment and scales the initial value by air density. For this case CCN concentrations were set at $350\left(\rho_{\text {air }} / \rho_{o}\right) \mathrm{cm}^{-3}$, where $\rho_{\text {air }}$ is air density and $\rho_{o}=1.225 \mathrm{~kg} \mathrm{~m}^{-3}$.

\section{Results}

\section{a. General Microphysical evolution}

Modeled precipitation initiated as raindrops via stochastic collision-coalescence in regions of high cloud water content just below the freezing level, resulting in the first reflectivity (Fig. 3b,c). Raindrops lifted and growing in updrafts began freezing at temperatures around $-10^{\circ} \mathrm{C}$ to form graupel. The time-height reflectivity (Fig. 3c) and graupel volume (Fig. 3d) show three maxima at about $45 \mathrm{~min}$, $55 \mathrm{~min}$ and $65 \mathrm{~min}$, each preceeded by a pulse in updraft volume. Peak cloud water contents (Fig. 3b) decreased significantly due to riming collection in the second and third reflectivity maxima as graupel volumes increased. Peak updraft (not shown) reached a maxium of $19.5 \mathrm{~m} \mathrm{~s}^{-1}$ at $40 \mathrm{~min}$, dropping to $10.2-12.1 \mathrm{~m} \mathrm{~s}^{-1}$ during the significant electrical period of 60-74 min. After $74 \mathrm{~min}$, peak updraft fell steadily to $6 \mathrm{~ms}^{-1}$ by $82 \mathrm{~min}$, where it remained for the rest of the simulation $(85 \mathrm{~min})$.

The third storm pulse was distinguished from the previous ones by growth in height of the $30 \mathrm{dBZ}$ height from about $-20^{\circ} \mathrm{C}$ to $-30^{\circ} \mathrm{C}$, the development of updraft above $6 \mathrm{~km}$, and substantial increase in graupel volume, resulting in electrification sufficient for lightning (10 flashes over $11 \mathrm{~min}$ ). Upward ice crystal flux through the $-10^{\circ} \mathrm{C}$ isotherm (not shown) also increased dramatically from 55 to $60 \mathrm{~min}$. Some ice crystals initiated from vapor deposition on ice nuclei, and these crystals helped initiate freezing of supercooled rain drops. A larger number of ice particles were produced by rime splintering (Hallett-Mossop process) in the temperature range of -8 to $-3^{\circ} \mathrm{C}$, and ice splinters were also produced by freezing drops at a chosen rate of one splinter per drop.

\section{b. General Electrical Evolution}

In the first and second reflectivity cores, graupel gained mostly positive charge from rebounding collisions with ice 


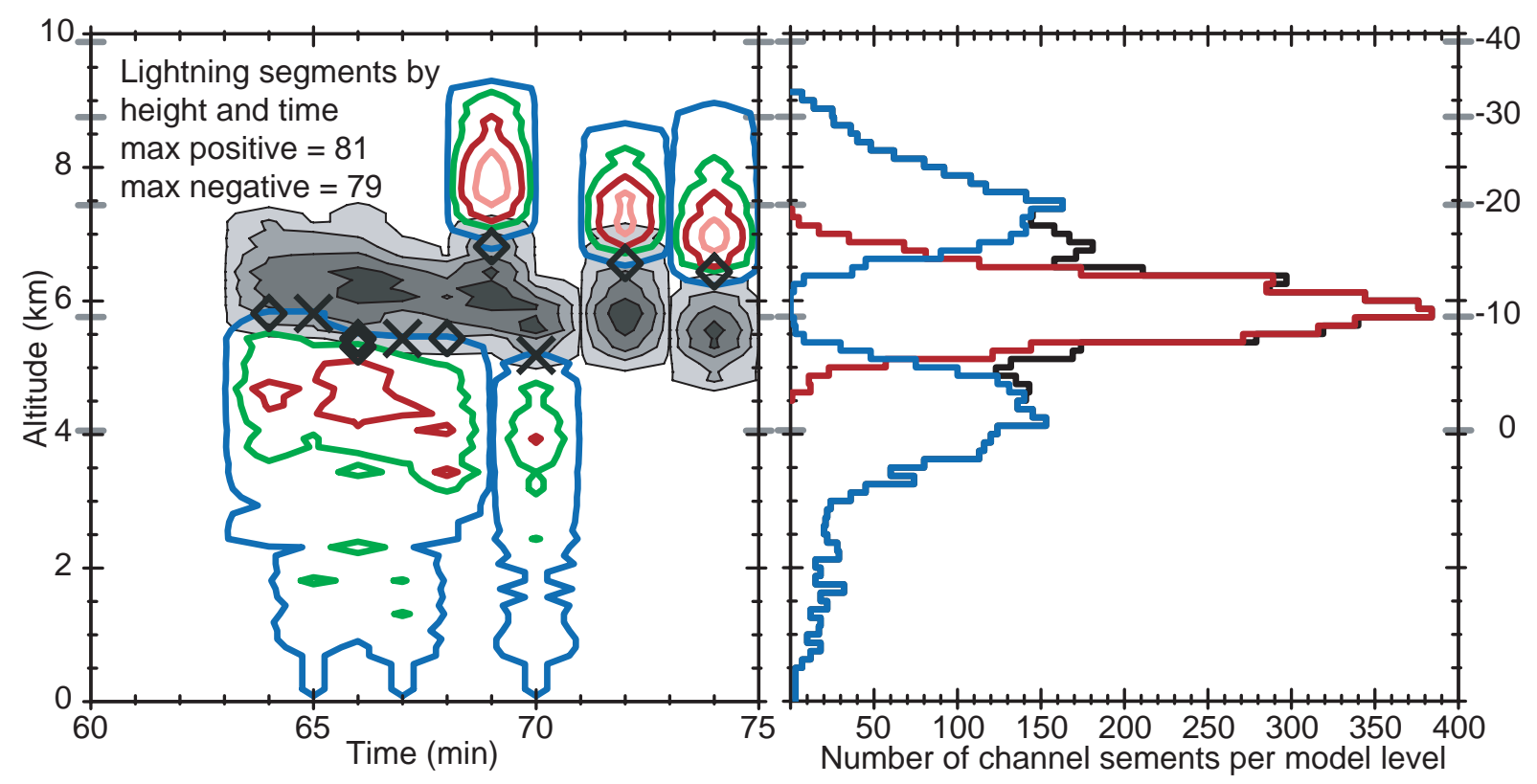

FIG. 5. (a) Time-height lightning channel segments per model level (negative: colored contours, positive: gray-filled contours). Contour levels are $0.75,10,25$, and 50 segments per level. (b) Total channel segments per model level: total (black), negative (blue) and positive (red).

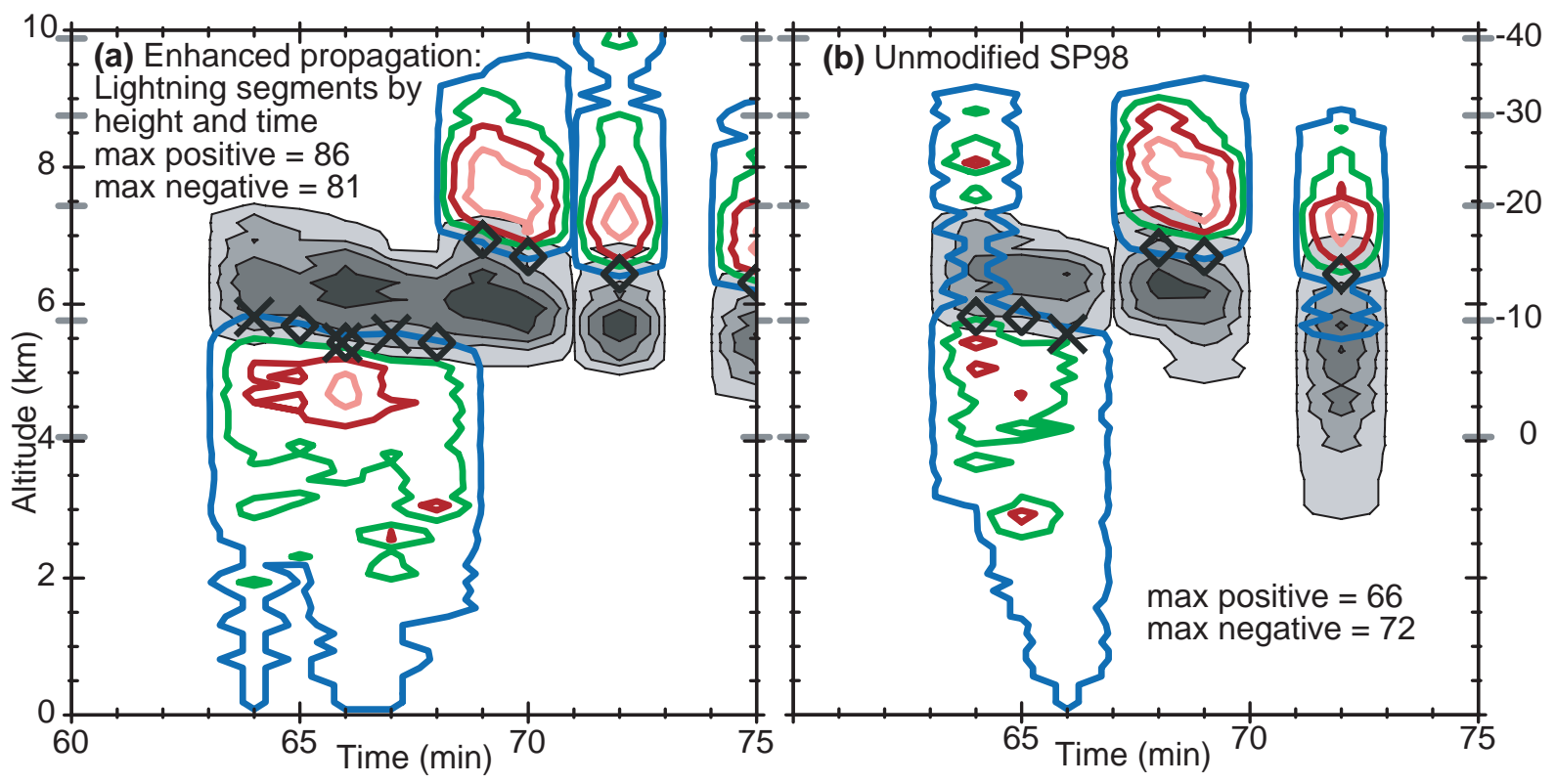

Fig. 6. As in Figure 5a but (a) with the propagation threshold factor reduced from 0.43 to 0.40, which results in the first flash reaching ground or (b) Use of the unmodified charge reversal curve (Fig. 1). The IC flash at $72 \mathrm{~min}$ in (a) propagated up into a cloud turret that was not accessed under the higher propagation threshold. The first IC flash in (b) at $64 \mathrm{~min}$ had a negative branch that propagated northwestward and upward into clear air. Contour levels are $0.75,10$, 25, and 50 segments per level (negative: colored contours, positive: gray-filled contours). 
crystals in the temperature range of -5 to $-15^{\circ} \mathrm{C}$ (Fig. $4 \mathrm{a}$, $45-55 \mathrm{~min}$ ) or roughly $5-6 \mathrm{~km}$ altitude. The positivelycharged graupel had much greater fall speed than the negatively-charged small ice particles, whose charge remained much more concentrated and is evident at about $5 \mathrm{~km}$ in Fig. 4c. Charge separation was appreciable but insufficient for lightning, with peak electric fields magnitudes remaining below $50 \mathrm{kV} \mathrm{m}^{-1}$.

Positive noninductive charging of graupel increased again at lower levels $\left(5-7 \mathrm{~km},-5\right.$ to $\left.-15^{\circ} \mathrm{C}\right)$ from 55 to $65 \mathrm{~min}$ (Fig. 4a). At the same time, graupel charged negatively at higher altitudes $(6-9 \mathrm{~km})$, where temperatures and rime accretion rates were lower. This combination of lower positive and upper negative charge separation resulted in three main charge regions by height, evident in the timeheight net charge (Fig. $4 \mathrm{~d}$ ): lower positive charge at $4-5 \mathrm{~km}$ (graupel), main negative charge at $5-7 \mathrm{~km}$ (ice crystals and graupel), and upper positive charge at $7-9 \mathrm{~km}$ (ice crystals and snow). Negative charge at higher altitudes $(8-10 \mathrm{~km}$ in Fig. 4c,d) is primarily in screening layers, which form from ion attachment to small cloud particles at cloud top. The lower positive region in Fig. 4b was attached to fasterfalling graupel and spread out vertically, and showed up as a clear peak when only when the charge separation rates are higher (Fig. 4a)

Inductive charge separation between graupel and small droplets was allowed, but integrated rates were always at least an order of magnitude smaller than noninductive charging and therefore not shown. We suspect that the effects are weaker than seen by Mansell et al. (2005) because the two-moment scheme properly accounts for depletion of droplet concentration, whereas the single-moment scheme assumed a constant droplet concentration. In the single moment scheme, a loss of droplet mass reduces droplet size, but not concentration, until the minimum allowed droplet size of $5 \mu \mathrm{m}$ is reached.

Lightning activity is summarized in Fig. 5 and Table 1. In the first five minutes of lightning activity, six flashes initiated between the main negative and lower positive charge regions, two - CG flashes and four intracloud (IC) flashes. The upper positive charge first became involved in lightning with the seventh flash $(68: 12)$ and then again with the final (IC) flashes. The effects of the three upper IC flashes on the net positive charge are noted in Fig. $4 \mathrm{~b}$ by arrows, which point to the sharp reductions in net positive charge. As would be expected from basic physics, the peaks in total positively and negatively charged lightning channel segments (Fig. 5b) correlate very well with the average heights of the charge layers (Fig. 4d, 65-70 min), more specifically with the maxima and minima in electric potential (e.g., MacGorman et al. 1981, 2001; Coleman et al. 2003) which are generally offset from the charge extrema.

\section{c. Lightning sensitivity}

Lightning activity from two sensitivity tests is shown in Fig. 6. In the first test, the critical propagation threshold factor $f_{\text {crit }}$ was reduced to see if the first flash could become $-\mathrm{CG}$ rather than IC. A reduction from 0.43 to 0.40 was sufficient to achieve a -CG flash, but three of the six lower flashes still did not reach ground. Otherwise, the lightning was quite similar to the control run: 10 total, $3-\mathrm{CG}, 3$ lower IC, and 4 upper IC flashes.

The second sensitivity test (Fig. 6b) shows results using the unmodified Saunders and Peck (1998) charge separation curve (Fig. 1). The reduction in positive charge transfer to graupel at lower altitude (higher temperature), or even reversal to negative charge transfer, results in only one -CG flash and two lower IC flashes. Three upper IC flashes were produced, as the control run did.

\section{d. Charge and reflectivity structure and lightning}

The evolution of charge and potential from just before the first flash to just after the second flash is represented at 20-second intervals in Fig. 7. The pre-flash structure (Fig. 7a) had three main charge regions, with the upper positive charge being the weakest. This structure might be described as a "bottom-heavy" tripole charge structure, which conventionally implies a strong upper positive charge and much smaller lower positive charge region. The first flash makes substantial reductions in the maximum positive and negative charge densities and in the maximum negative potential (Fig. 7b). Maximum positive potential wss only slightly affected since the upper positive charge wss not involved and maintained its potential, although the lower positive maximum was eliminated (at least in the plane). Over the next minute (Fig. 7c,d), charge and potential maxima increased again until the -CG flash at 64:20 (Fig. 7e), which completely eliminated the negative potential region in the plane shown. Negative potentials quickly regenerated, however, just 20s later (Fig. 7f).

The growth in strength of the upper positive charge region is evident in comparing first and last panels of Fig. 7. In Fig. 7a, the main upper positive charge was in a small region on the right-hand side of the structure $(X=20$ $23 \mathrm{~km}$ ), where the thin layer of positive charge at the left edge $(X=17 \mathrm{~km})$ is a screening layer resulting from positive ions attaching to hydrometeors at the cloud boundary. Negative screening layers are also found above and to the lower right side of the stronger upper positive charge. Less than two minutes later (Fig. $7 \mathrm{f}$ ), the maximum potential contour in upper positive charge grew from $15 \mathrm{MV}$ to $45 \mathrm{MV}$. The negative screening layers also grew thicker and began to extend farther to the west $(X=18-20 \mathrm{~km})$, where the positive charge also increased.

Simulated radar reflectivities near the times of four lightning flashes are shown in Fig. 9. Note that the re- 

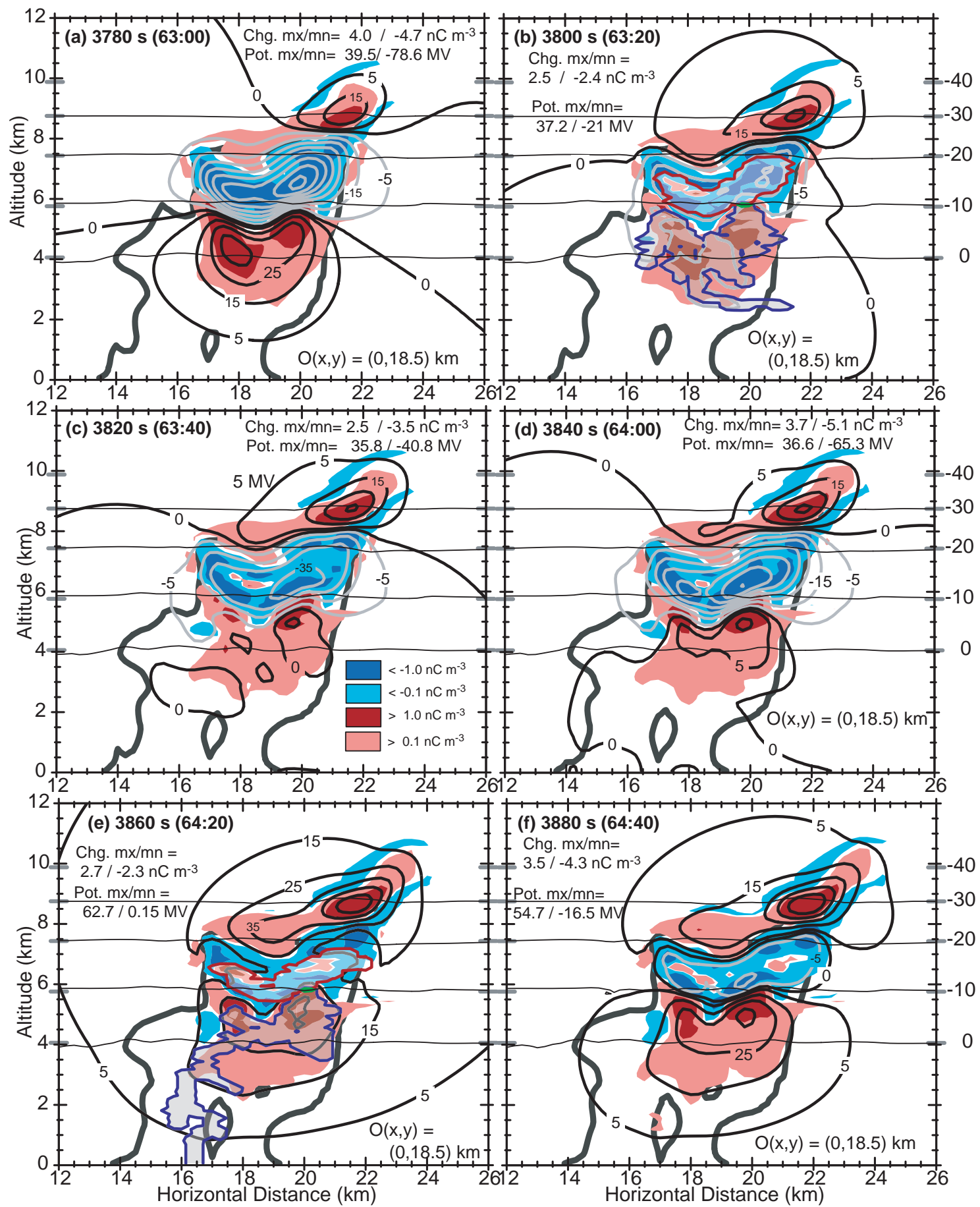

FIG. 7. Charge structure (color fill), electric potential (heavy contours), and lightning projection (positive channels in red outline, negative in blue, both with transparent gray shading) at $20 \mathrm{~s}$ intervals. Panel (a) shows structure $20 \mathrm{~s}$ before the first lightning flash (b). Panel (e) shows the first - CG flash (second lightning) of the simulation. The wide curve is the $30 \mathrm{dBZ}$ reflectivity contour. Hairline contours indicate air temperature $\left(-30^{\circ} \mathrm{C}\right.$ to $0^{\circ} \mathrm{C}$ by $\left.10^{\circ} \mathrm{C}\right)$. The origin point of the slice relative to the model domain is given by $O(x, y)$, and horizontal distance is along a line at $-16.7^{\circ}$ from the $\mathrm{X}$-axis. 

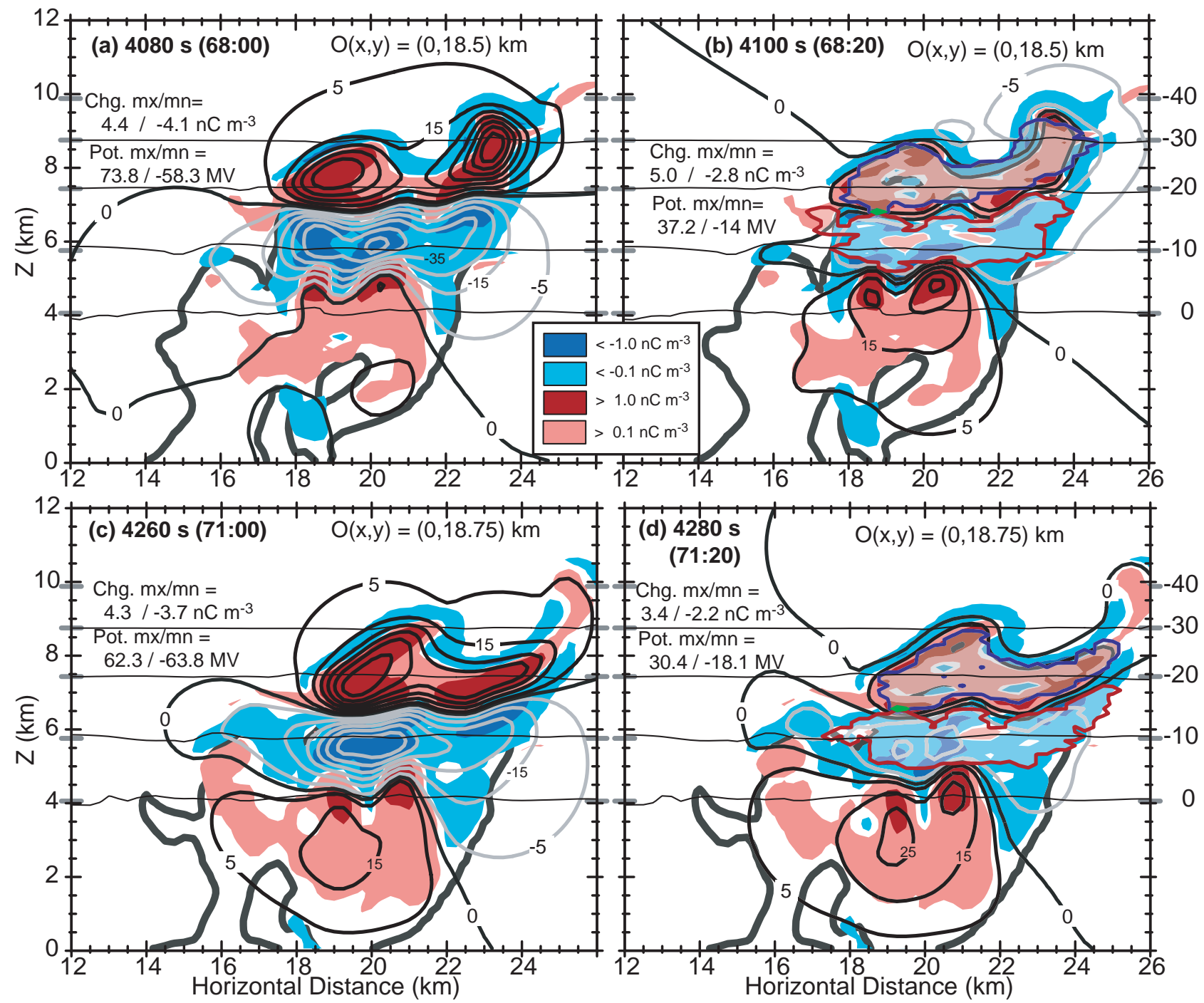

FIG. 8. As for Figure 7 but for first (a, b) and last (c, d) of the three upper IC discharges. Charge structure (color fill), electric potential (heavy contours), and lightning projection (positive channels in red outline, negative in blue).

flectivity slices are taken $250-500 \mathrm{~m}$ north of the planes in Figs. 7 and 8 , indicated by the y-value of the origin $O(x, y)$ noted on each panel. At $3800 \mathrm{~s}$, two reflectivity maxima are seen at $X=16 \mathrm{~km}$ and $X=20 \mathrm{~km}$, with lightning initiating in the rightmost reflectivity (Fig. 9a). The two regions of higher positive charge in the lower positive charge region (Fig. 7a) correspond to the two regions of updraft at $X=17 \mathrm{~km}$ and $X=19.5 \mathrm{~km}$, just below the $-10^{\circ} \mathrm{C}$ isotherm. By $3860 \mathrm{~s}$ a new region of $45 \mathrm{dBZ}$ had grown at $X=17 \mathrm{~km}$ between the decaying left core and growing right-hand-side core. Lightning channels from the flashes at both times penetrated this region, which had substantial charge (Fig. 7b,e). Later, at 4100 s (Fig. 9c), the middle region had continued to grow and now became the source of initiation of the upper IC flashes (Fig. 8b,d), with channels propagating back into the rightmost cell. Fig. 9d shows the last flash of the storm, at which time the higher reflectivities (> $40 \mathrm{dBZ}$ ) had fallen below the freezing level.

Figure 9 also exhibits the interplay of lightning and cell development. The simulated flashes at 63:20 and 64:20 initiated in the eastern (rightmost) reflectivity core and penetrated within that core and westward into the neighboring one (Figs. 9a,b). The core to the west later initiated its own lightning flash at 68:20 (Fig. 9c), which propagated back into the eastern cell. Similar behavior was observed by Bruning et al. (2007). The last flash at 74:00 also penetrated westward into the newer weak cell, whose charge at an earlier time can be seen in Fig. 8d. Lightning never initiated in this far western cell.

At the mature stage of $69: 20 \mathrm{~min}$, the lower positive 

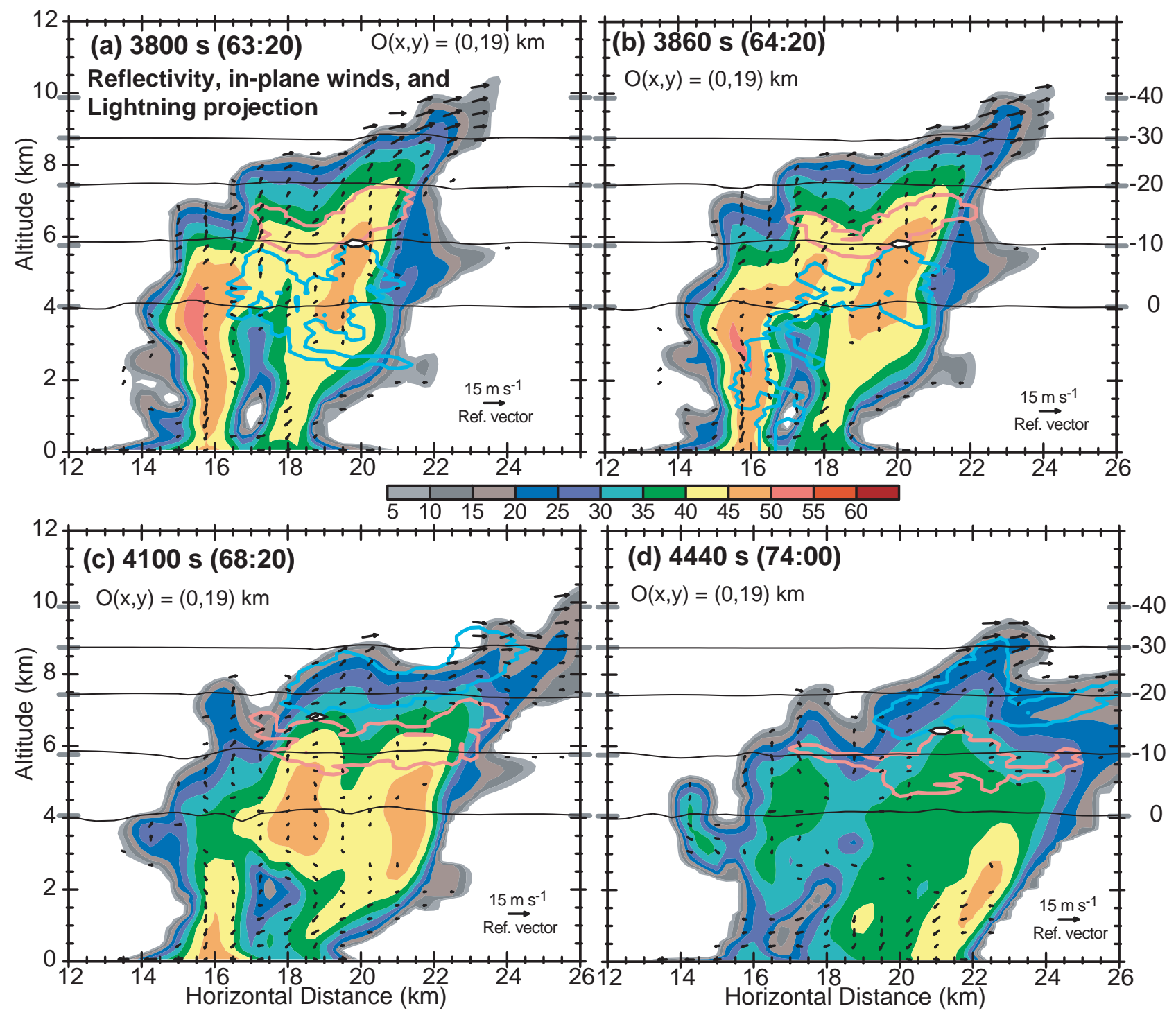

Fig. 9. Reflectivity and winds in a representative plane that is $500 \mathrm{~m}$ North of the plane used in Figure 7 . Lightning flash outlines and initiation points are projected in to the plane: Positive channels (red outline), negative channels (blue outline), initiation points (white-filled area with black outline). Isotherms are represented by thin black contours. (a) First lightning flash (IC flash, Figure 7b). (b) First - CG flash (second flash overall, Figure 7e). (c) First of the three upper IC flashes. (d) Last of the three upper IC flashes 
Time $=4160 \mathrm{~s}(69: 20)$
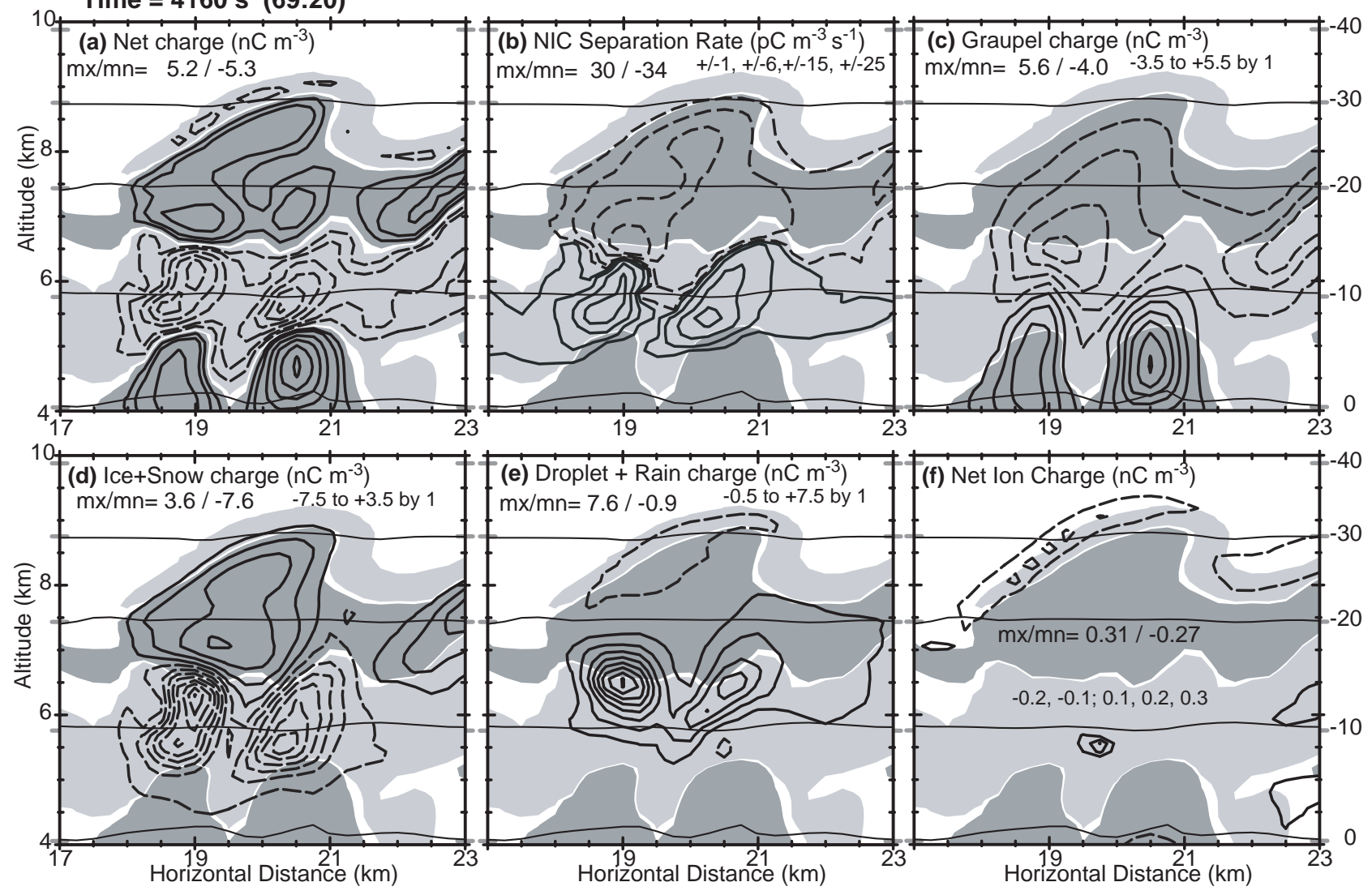

FIG. 10. Net charge, charging rates, and hydrometeor charges at 69:20 just before the last -CG flash. Positive contour lines are solid, negative lines are dashed. Background shading is for net charge $>0.1 \mathrm{nC} \mathrm{m}^{-3}$ (darker) and $<-0.1 \mathrm{nC} \mathrm{m}^{-3}$ (lighter). (a) Net charge, (b) Noninductive charge (NIC) separation rate (graupel with ice and snow), (c) Charge on graupel, (d) Charge on ice crystals and snow, (e) Charge on cloud droplets and rain, and (f) Net free ion charge (note different scale on contours). Maximum and minimum values $(\mathrm{mx} / \mathrm{mn})$ are indicated on each panel.

charge region (Fig. 10a) consisted mostly of positivelycharged graupel (Fig. 10c). The lower part of the main negative charge region also had positive graupel particles but more negative charge on small ice crystals and snow (Fig. 10d). The upper parts of the main negative region held negatively-charged graupel, cloud ice and snow, along with positively-charged cloud droplets and drizzlesized rain drops (200 $\mu$ m diameter, Fig. 10e), which gained charge primarily from attachment of lightning-produced ions. (Rain drops may also be charged if they form by coalescence of charged cloud droplets.) A large fraction of ice crystals rising into the upper part of the negative charge region (about -12 to $-17^{\circ} \mathrm{C}$ ) grew sufficiently by vapor deposition to be converted into snow particles, which carried most of the charge in the upper positive charge region. Negatively-charged graupel also existed in the the upper positive charge region. Some portions of the thick negative screening layers at the top of the storm actually extended above the cloud boundary by up to $250 \mathrm{~m}$ (two grid points) as free ion charge (Fig. 10f), suggesting that significant small ion charge densities $\left(>0.1 \mathrm{nC} \mathrm{m}^{-3}\right)$ may exist at the cloud exterior.

\section{e. Electric field and energy evolution}

Some effects of lightning on the maximum electric field magnitude and storm electrical energy can be seen in the time series plots in Figs. 11 and 12. The initial growth of the maximum electric field is essentially linear, although the initial energy growth has increasing slope. The storm is small, so each flash can reduce the total electrical energy by a substantial fraction (listed in Table 1), from $33 \%$ to almost $80 \%$. Fig. 11 also shows a recovery of electric field and energy after the last simulated lightning flash (at 73:48), but was insufficient to initiate lightning before charge separation ceased to be greater than non-lightning dissipation processes. For comparison, the total gravitational energy of graupel at $65 \mathrm{~min}$ was $2.2 \times 10^{12} \mathrm{~J}$, about three orders of magnitude greater than the electrical energy. (This does 


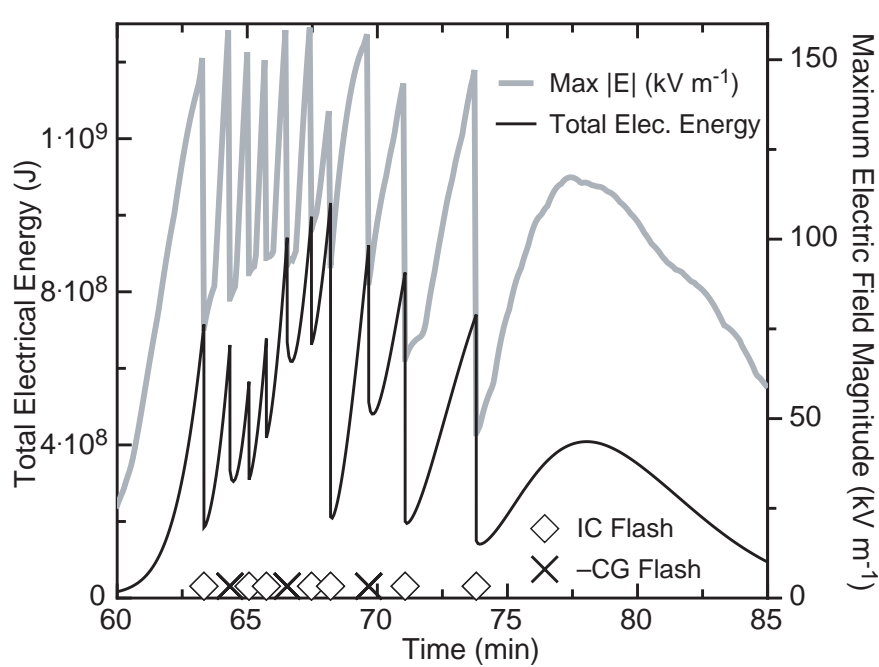

Fig. 11. Total electrical energy and maximum electric field magnitude time-evolution. The time resolution is the model time step $(4 \mathrm{~s})$. Percentage changes in electrical energy are listed in Table 1.

not necessarily imply that locally the electric force could not be an appreciable fraction of the gravitational force in regions of large electric fields.)

A more detailed picture of electric field and energy is presented in Fig. 12a. Here it is evident that the electric field recovery tended to have an initial slow linear growth followed abruptly by faster linear growth. This behavior appears to be a result of continued diffusion of ions deposited by lightning, particularly when the ions are released in regions with fewer small hydrometeors, such as in the lower positive charge region. Some time is needed for the new ions to drift and attach to hydrometeors, less time when many small particles are present. Helsdon et al. (1992) noted that lightning ions in cloudy regions had mostly attached to hydrometeors within $2 \mathrm{~s}$, whereas in precipitation regions with low concentrations of small hydrometeors the density of lightning ions could remain significant for $30 \mathrm{~s}$ or more. They also noted continued reduction in charge on snow particles and on electric field for their intermediate (L3) flash case (Helsdon et al. (1992), Figs. 6 and 8) due to diffusion of lightning ions. The storm simulated by Helsdon et al. (1992) had a high assumed CCN concentration and thus high assumed cloud droplet concentrations. In the present case, the cloud droplet concentrations are much lower as results of lower CCN concentrations and scavenging by graupel, so that droplet concentrations in the main negative charge region were typically as low as $10-30 \mathrm{~cm}^{-3}$, which tends to decrease the rate of ion attachment. Helsdon et al. (1992) used single-moment microphysics, so droplet concentrations were much less affected by scavenging, keeping droplet concentrations and attachment rates higher. Thus we expect a longer life-
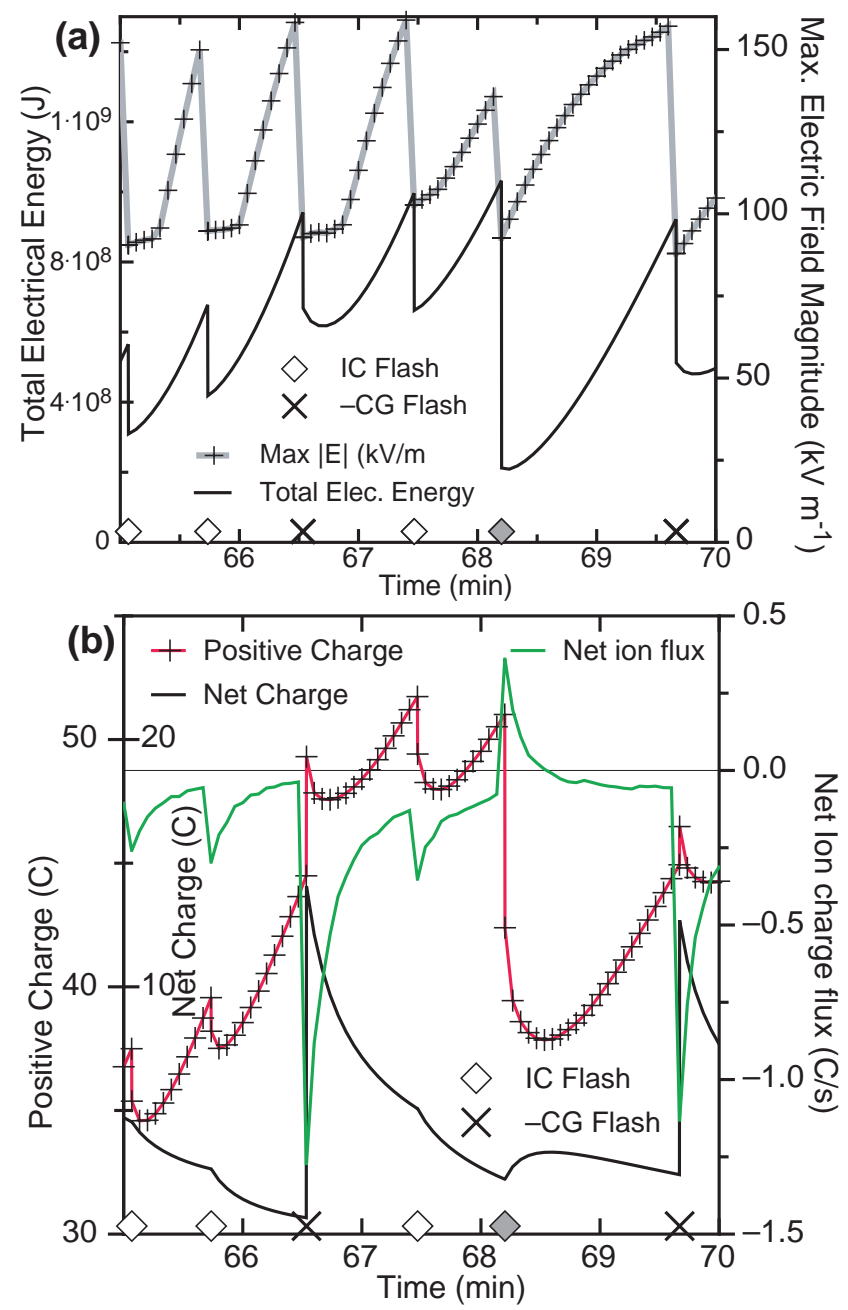

FIG. 12. Step-by-step time-evolution of (a) maximum electric field and total electrical energy, and (b) net ion charge flux into the model domain and domain total net charge and positive charge. The time resolution is the model time step $(4 \mathrm{~s})$. The shaded IC flash symbol (diamond) indicates a normal-polarity discharge (negative vertical dipole moment) between the main negative and upper positive charge regions. 


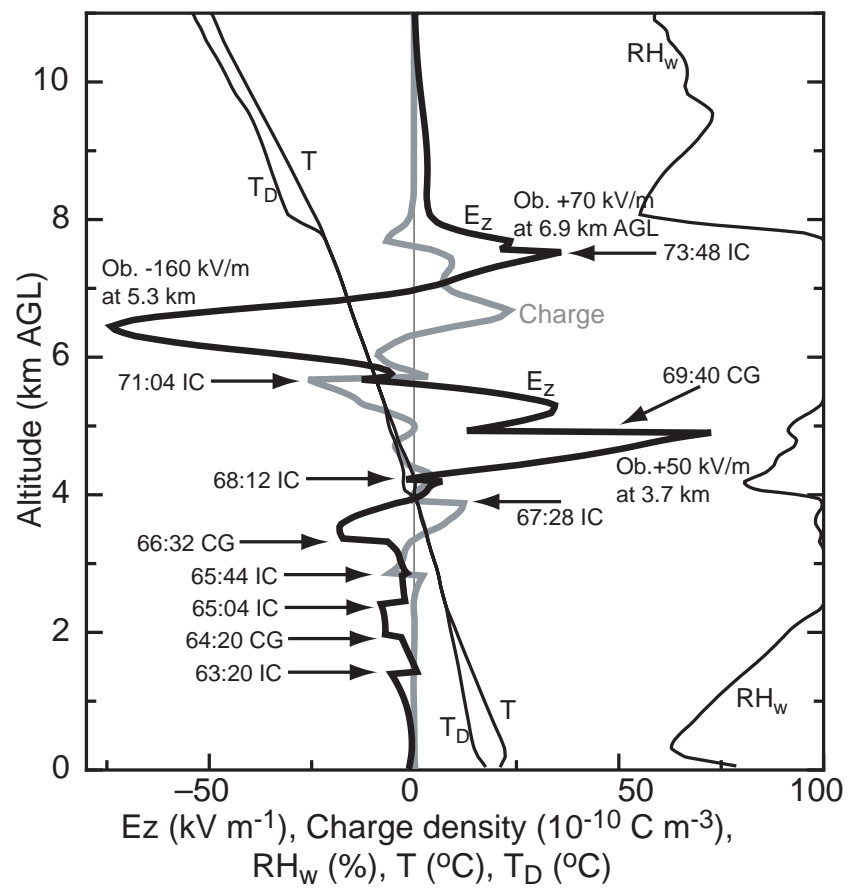

FIG. 13. Simulated balloon sounding profile of vertical electric field component $E_{z}$, net charge interpolated to the balloon location, air temperature $T$, dewpoint temperature $T_{D}$, and relative humidity (with respect to liquid water) $R H_{w}$. The simulated balloon trajectory assumed a rise rate of $10 \mathrm{~m} \mathrm{~s}^{-1}$ relative to the local vertical wind motion. The times and types of all 10 simulated flashes are indicated.

time for lightning ions deposited within the main negative charge region than was seen in Helsdon et al. (1992). The pre-existing charge on hydrometeors also affects the rate of ion attachment. For example, if positive ions attach to cloud droplets after a flash, then, after the next flash that deposits positive ions, attachment rates would be reduced because of the positive charge already attached. The plot of maximum electric field magnitude in Fig. 12a suggests that lightning ions continue to affect the field recovery for $4-5$ time steps, or $16-20 \mathrm{~s}$.

The field recovery after the first upper IC flash does not follow the pattern of the previous recoveries, because the main field growth has switched from between the lower positive charge region and the main negative region to between the main negative and upper positive regions, where small hydrometeors are more plentiful and lightning ions attach more quickly, particularly in the upper positive region. Additionally, ion mobilities are greater at higher altitude, contributing to faster attachment.

Fig. 12a also plots the total electrical energy in the model domain, where a difference is seen in the response to IC and -CG flashes. The continued decrease in energy for a few time steps after -CG flashes appears to be a response in the ion currents into and out of the domain (Fig. 12b). The monopole moment from a CG flash causes a significantly larger change than IC flashes in the electric fields at the domain boundaries. The larger-scale ion currents acted to restored the net domain charge back toward pre-flash values, reducing the electric fields (and potentials) outside of the storm. (Compare the electric potentials in Figs. 7e and f.)

Fig. 12b shows lightning effects on the net charge, the total positive charge, and ion charge flux into the model domain. The total positive charge always showed some reduction after each flash (even after the -CG flash, which had just increased the total positive charge). This reduction was a result of continued drift of lightning ions into regions of opposite charge. The ion flux responds more to the upper part of IC flashes (i.e., opposite to the dipole moment) and, of course, responds more strongly to the monopole charge from the -CG lightning. Ion flux and CG flashes were the dominant sources of net charge to the storm.

\section{f. Simulated balloon sounding}

A set of simulated instrumented balloon soundings were generated in the model, one of which is plotted in Fig. 13. The sounding was initiated at $59 \mathrm{~min}(3540 \mathrm{~s})$ with an assumed rise rate of $10 \mathrm{~m} \mathrm{~s}^{-1}$ relative to vertical air motion. The simulated sounding resembled the observed electric field structure (vertical component) quite well in terms of the sequence of the main positive and negative excursions, though generally the peaks were at higher altitudes than in the observed sounding. Approximate peak values and AGL altitudes from the observed sounding are noted in Fig. 13 next to the simulated peaks at $5 \mathrm{~km}, 6.5 \mathrm{~km}$, and $7.5 \mathrm{~km}$. The simulated peaks are consistently at higher altitudes by $500-1300 \mathrm{~m}$. The difference in altitudes could be simply a result of the modeled sounding occurring earlier in the storm life-cycle when charge interfaces were higher. It is evident from Figs. $4 \mathrm{~b}-\mathrm{d}$ that the main charge regions descended with time. By about $80 \mathrm{~min}$ the charge interfaces between the main negative and upper positive and between the upper positive and negative screening layers were closer in altitude to the upper two electric field peaks in the sounding, which the real balloon traversed after the last lightning flash.

The simulated sounding maintained water saturation from about $5.3 \mathrm{~km}$ to $7.8 \mathrm{~km}$, suggesting that the region sampled by the observed sounding, which showed subsaturation, was farther into decay stage than for the same altitudes in the simulated sounding. The model did not produce any high relative humidities in the boundary layer that were indicated by the observed sounding. It is possible that the microphysics parameterization underestimates evaporation of rain, or, alternatively, that splashing of rain drops on the radiosonde resulted in unrealistically high $\mathrm{RH}$ 
measurements. (The balloon was launched in rain during the TELEX storm.) The model sounding also has a layer of cool storm outflow air in the lowest $300 \mathrm{~m}$ above the surface, but the observed sounding has no indication of storm outflow. The model presently has no surface physics (e.g., drag or heat and moisture fluxes) that might play roles in modifying downdraft air that reaches the surface.

\section{Discussion}

The observed TELEX storm (Bruning et al. 2007) produced 30 total lightning flashes over 38 minutes. Of these, 15 flashes were identified by the National Lightning Detection Network (NLDN) as -CG flashes. Lightning mapping array (LMA) data analysis suggests that two more flashes were likely also negative -CG but missed by the NLDN. We judged three of the observed flashes between the main negative and lower positive charge regions to be IC flashes, based on LMA analysis and lack of a detection by the NLDN. The remaining 10 flashes were IC flashes involving the main negative and upper positive charge regions, with a few flashes also extending from the upper positive charge into the lower positive charge. The simulated storm had 10 flashes over 11 minutes for a comparable flash rate. The simulation also reproduced initial lightning in the lower charge regions followed by lightning in the upper charge regions. Perhaps fortuitously, the ratio of upper to lower flashes in both the observed and simulated storms were both about 1:2. The fraction of lower IC flashes in the simulation $(>50 \%)$, however, was much higher than in the observed storm, and will be discussed further below.

\section{a. Initial and $C G$ lightning activity}

One of the notable features of the 28-29 June 2004 TELEX storm was that the first six lightning flashes were all -CG flashes, suggesting at least a negative dipole structure in which the mid-level negative charge was enhanced relative to the lower positive. If equal magnitudes of positive and negative charge were available to lightning, energetics would favor an IC flash. The initial lightning in the model, on the other hand, was a mixture of $-\mathrm{CG}$ and IC flashes, although the first flash can be a -CG with a slightly reduced propagation threshold. Overall, however, the simulated storm and lightning are consistent with the observed flash behavior and with inferences based on those observations (charge structure in particular). Cases with exclusively IC lightning in a lower dipole (inferred negative over positive charge, Fig. 14a) at the beginning stages of a storm have also been observed, for example, by Qie et al. (2005) (with surface field-change data) for a low flash-rate storm on the Tibetan plateau and by Wiens et al. (2005) (with lightning mapping data) for a higher flash rate storm (Kansas, USA).

The shortcomings of the lightning parameterization may explain this discrepancy in the initial lightning (CGonly vs. IC and CG). A number of the observed -CG flashes either did not appear to connect immediately to ground from the initial negative leader breakdown or had subsequent breakdown activity more like IC lightning, as also observed by Coleman et al. (2008) for New Mexico storms. This suggests that the contact to ground was only a portion of the total flash. In other words, the -CG flash may have affected only part of the upper positive branching region. The lightning parameterization, on the other hand, maintains a strong feedback between the positive and negative branches to maintain neutrality (before ground contact), and assumes that channels always maintain high conductivity. The assumption of continuously highly conductive and connected channels throughout the discharge is certainly not the case in most lightning, as evidenced, for example, by current cut-off and recoil leaders (e.g., Mazur 2002), where the channel is inferred to have cooled to lower conductivity and is then re-ionized to higher conductivity by the passage of a potential wave. The simulated -CG flashes therefore very likely overestimate the amount of charge brought up to the negative charge region, and thus could reduce the potential bias on the next flash so that it does not reach ground, as may have been the case in the observed storm for the first low IC flash. Note in Table 1 that the IC flash at 65:04 following the first CG flash had a much less negative channel potential (i.e., closer to zero), significantly reducing its likelihood of reaching ground. The first of the observed low, inverted IC flashes was the eighth flash of the storm (the second flash in Fig. 8 of Bruning et al. 2007). This observed flash occurred just after the first flash between the main negative and upper positive charge regions, which may have reduced the negative charge sufficiently to be more equal in magnitude to the lower positive charge.

Bruning et al. (2007) noted that although lightning did not indicate an upper positive charge before the seventh flash, that does not rule out the presence and influence of an upper positive region. The assumed (and modeldemonstrated) need for a substantial bias of the channel potential to promote CG flashes leads to hypothesis of at least two mechanisms: (1) The lower positive charge is reduced relative to the main negative by sedimentation of positively-charged graupel and raindrops to the ground, and (2) Charge separation in the upper part of the storm enhances the negative charge region while also creating an upper positive charge region. Both mechanisms are active in the model simulation, but the time scale for graupel and rain to fall more than $5 \mathrm{~km}$ to ground is on the order of $8 \mathrm{~min}$, assuming an average fall speed of $10 \mathrm{~m} \mathrm{~s}^{-1}$, suggesting that it would be only a secondary effect. The main issue with the second mechanism (upper charge separation) is that it must be weak enough that lightning is delayed in the upper regions. 


\begin{tabular}{lrrrrrrrr}
\hline $\begin{array}{l}\text { Time } \\
(\text { min:sec })\end{array}$ & $\begin{array}{r}\text { Flash } \\
\text { Type }\end{array}$ & $\begin{array}{r}\text { Initial } \\
\phi_{r e f} \\
(\mathrm{MV})\end{array}$ & $\begin{array}{r}\text { Final } \\
\phi_{\text {ref }} \\
(\mathrm{MV})\end{array}$ & $\begin{array}{r}\Delta \phi_{\text {ref }} \\
(\mathrm{MV})\end{array}$ & $\begin{array}{r}\text { Dipole } \\
\text { Mom. } P \\
(\mathrm{C} \mathrm{km})\end{array}$ & $\begin{array}{r}\text { Charge } \\
\text { Transfer } \\
(\mathrm{C})\end{array}$ & $\begin{array}{r}\text { Altitude } \\
(\mathrm{km})\end{array}$ & $\begin{array}{r}\text { Change in } \\
\text { Electrical } \\
\text { Energy (\%) }\end{array}$ \\
\hline $63: 20$ & IC & -42.9 & -14.6 & 28.3 & 20.7 & $(10.0)$ & 5.4 & -74.2 \\
$64: 20$ & -CG & -55.1 & -20.2 & 34.9 & & 10.4, & 6.5 & -49.6 \\
$65: 04$ & IC & -6.6 & -4.7 & 1.8 & 12.2 & $(6.6)$ & 5.4 & -45.3 \\
$65: 44$ & IC & -26.0 & -14.9 & 11.1 & 17.6 & $(7.2)$ & 5.0 & -38.3 \\
$66: 32$ & -CG & -45.6 & -22.5 & 23.0 & & 13.4, & 6.0 & -29.0 \\
$67: 28$ & IC & -31.0 & -8.6 & 22.3 & 17.6 & $(8.0)$ & 5.1 & -33.5 \\
$68: 12$ & IC & -21.3 & 1.2 & 22.5 & -29.8 & $(15.5)$ & 7.1 & -79.4 \\
$69: 40$ & -CG & -52.3 & -19.5 & 32.8 & & 10.3, & 6.3 & -44.5 \\
$71: 04$ & IC & 14.5 & 3.5 & -11.1 & -21.5 & $(13.5)$ & 6.6 & -76.5 \\
$73: 48$ & IC & -16.1 & -4.0 & 12.1 & -21.5 & $(11.7)$ & 6.4 & -79.8 \\
\hline
\end{tabular}

TABLE 1. Individual simulated discharge characteristics. For $-\mathrm{CG}$ flashes, the channel potential $\phi_{\text {ref }}$ is the value just before contact with ground, at which point $\phi_{r e f}$ is reset to ground potential (zero). $P$ is the magnitude of the IC flash dipole moment vector with the sign of the vertical component, $P_{z} . P<0$ indicates 'normal' polarity, and in this case $\left|P_{z} / P\right|>0.84$. Charge transfer is the net charge transferred to the storm by CG flashes, or the amount of charge (in parentheses) deposited by the positive channels of IC flashes. Altitude for IC flashes is the height of the midpoint between the positive and negative charge centers, and for CG flashes it is the height of the monopole charge center.

The observed and simulated CG lightning behavior seem to be consistent with the data presented by Coleman et al. (2008), as well. Coleman et al. (2008) found a relationship between the time interval from initiation to ground contact of $-\mathrm{CG}$ flashes in New Mexico storms with the extent of horizontal branching detected by the Langmuir Laboratory LMA: The delay time increased as the horizontal branching increased in the initial downward breakdown. This is consistent with a continuum range starting from a very localized lower positive charge (fast -CG flash) and increasing positive charge (increased horizontal branching in $-C G$ ) to a positive charge that sufficiently balances the main negative charge to prevent -CG flashes (low, inverted IC flash). The surface electric field values presented by Coleman et al. (2008) are consistent with the relative magnitudes of the lower positive and main negative charges: "Fast" - CG flashes occurred with positive electric field, suggesting dominance of the main negative charge, while slower-CG flashes occurred with less positive or negative surface field, suggesting a stronger lower positive charge relative to the main negative.

Coleman et al. (2008) interpreted the fast -CG flashes as indicating the absence of a positive potential well, but alternative explanation lies in the relative magnitude (and three-dimensional extents) of the positive to the negative potential regions. Indeed, Coleman et al. (2008) noted that most -CG return strokes were followed by more negative breakdown at the same altitudes as the first sequence of breakdown, from which ambient positive charge would be inferred. The subsequent breakdown did not reach ground (IC-like flash behavior), however, which could be explained by action of the return stroke to deposit positive charge in the main negative charge region and reduce the rela- tive magnitude and volume differences between the negative and positive potential wells. The return stroke shifts the local potentials toward zero and causes the sharp negative change in surface electric field. Coleman et al. (2008) also noted positive surface electric field changes with some -CG flashes, particularly when the surface field was negative prior to the flash. The low inverted IC flashes in the simulation also caused positive excursions in surface field (not shown) by bringing negative charge closer to ground, suggesting that the overall effect of those observed -CG flashes was more like an IC flash, i.e., that the change in net storm charge was small and that the effect of the subsequent in-cloud discharge dominated over the charge deposited by the return stroke(s).

\section{b. Delay in upper IC lightning}

The noninductive charge separation rates shown in Fig 4a reveal that maximum negative charging rates are lower than the maximum positive rates. The integrated negative and positive charge separation rates, however, are roughly equal from $55 \mathrm{~min}$ to $65 \mathrm{~min}$, at which time the total negative exceeds total positive charge rates to graupel (not shown). At a low charge separation rate threshold, the volume of negative charge separation well exceeds the volume of positive charging, but the case is the opposite for high charge separation rates. The positive charging of graupel, then, occurs more intensely in a smaller region, at least up to about $65 \mathrm{~min}$, so that electric fields sufficient to initiate lightning occur first between the lower positive and main negative charge regions. The negative charge separation is responsible for enhancing the main negative charge relative to the lower positive charge and enabling 
(a) Negative dipole

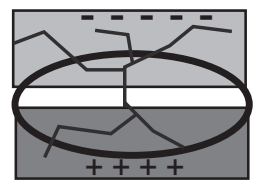

Low, inverted IC flashes (b) Bottom-heavy tripole

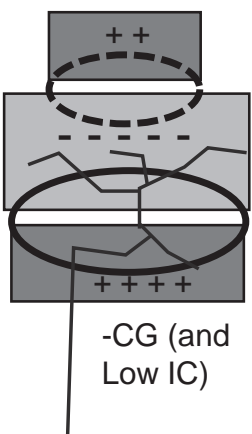

(c) Balanced tripole

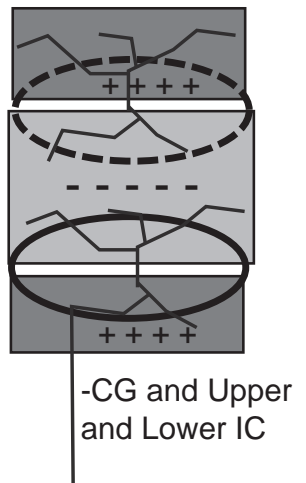

(d) Classic tripole

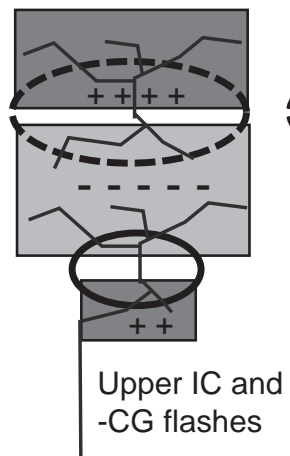

(e) Positive

dipole

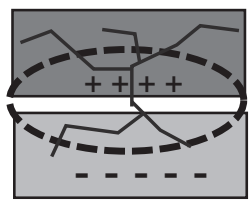

Upper IC flashes

Fig. 14. Simplified models of charge structures and underlying noninductive charge separation. Solid ellipses denote graupel gaining positive charge, dashed ellipses indicate negative charging of graupel. Significant charge regions are noted by the shaded rectangles (light shading for net negative, darker shading for net positive charge). For inverted polarity storms, simply reverse all signs.

-CG flashes. The delay in upper lightning is a result of the weaker intensity of the negative charging, but being within a greater volume led to upper IC flashes with dipole moment magnitudes greater than the lower IC flashes (Table 1).

\section{c. Charge descent}

Bruning et al. (2007) estimated a $3 \mathrm{~m} \mathrm{~s}^{-1}$ rate of decent of the upper charge layers involved in lightning. In the simulation, the interface between the upper positive and main negative charge regions descended from about $7 \mathrm{~km}$ (Fig. 8a) to $6.5 \mathrm{~km}$ (Fig. 8c) in three minutes, or roughly $2.8 \mathrm{~m} \mathrm{~s}^{-1}$, which agrees well. As noted above in Section 4f, the time-height layer net charge (Fig. 4d) exhibits the reduction in average height of the charge layers, which also generally reflects the decreases in heights of peak positive and negative charging of graupel (Fig. 4a). The time-height lightning plot in Fig. 5 additionally shows that lightning initiation points fell in altitude with time. In Fig. 9c and d it is seen that the reflectivity contours generally descended with the charge layers and flash initiation heights, consistent with the observations (See Fig. 8 in Bruning et al. 2007). Figure 10c shows a maximum negative graupel charge just below the main negative-upper positive charge interface, and this is generally true where graupel is gaining negative charge noninductively. In other words, the altitude of the negative-positive interface is driven by the altitude of maximum graupel negative charging rate, which in turn depends on ice collision rate and impact speed, ambient temperature and rime accretion rate. In the simulated storm, those conditions are fairly well tracked by the $35 \mathrm{dBZ}$ reflectivity top or by a graupel mixing ratio of about $0.8 \mathrm{~g} \mathrm{~kg}^{-1}$ (not shown).
Bruning et al. (2007) discussed the possible effect of small hydrometeors that collect ions from lightning discharges on the interface between the upper positive and main negative charge regions. This "masking" effect is seen to a degree in the model, but mainly associated with cloud droplets and small rain drops rather than ice crystals. Lightning ions also attach to ice crystals and snow and reduce the charge they carry, but these particles can recharge via noninductive charge separation if they are in an active charging region. Figure 10e shows positively-charged liquid drops that gained their charge by ion attachment and were then transported upward by updraft. The presence of the positive drops acts to bring the lower boundary of the upper positive charge downward by roughly $250-400 \mathrm{~m}$ at most. The effect is quite stable in time because the charged drops tend to be collected by graupel, limiting how far the drops can carry their charge. Thus we find that some masking does occur but does not shift the boundary between net positive and negative charge over time.

\section{d. Field recovery after lightning}

The recovery of the maximum electric field and total electrical energy after a lightning flash is a combination of continued collisional charge separation coupled with differential sedimentation of oppositely charged particles. To examine the effectiveness of sedimentation of pre-existing charged particles alone, the model was restarted at 68:20 (4100 s), just after the first upper IC flash, with noninductive charge separation deactivated. No lightning occurred. The maximum electric field magnitude was $103 \mathrm{kV} \mathrm{m}^{-1}$ at the start and did increase to a maximum value of $137 \mathrm{kV} \mathrm{m}^{-1}$ one minute later at $69: 20$, after which it oscillated slowly in the range of $126-139 \mathrm{kV} \mathrm{m}^{-1}$ until peaking 
again at roughly 71:00, at which time the total electrical energy also peaked. The electrical energy more than quadrupled from a starting value of $230 \mathrm{MJ}$ to $956 \mathrm{MJ}$, slightly exceeding the energy (921 MJ) in the control run just before the final -CG flash at 69:40 (Fig. 12a) but taking $80 \mathrm{~s}$ longer to reach that value. After 71:00 the maximum field and total energy declined steadily to $11.5 \mathrm{kV} \mathrm{m}^{-1}$ and 5.4 MJ, respectively, by the end of the simulation (85:00), compared with $>50 \mathrm{kVm}^{-1}$ and $94 \mathrm{MJ}$ with continued charge separation (Fig. 11).

\section{Conclusions}

The basic behavior of the 28-29 June 2004 multicell storm was quite well represented by the model simulation, whose results support some of the interpretations previously made from observations alone. The initial dominant negative-over-positive charge structure with a weaker upper positive charge ("bottom-heavy" tripole, Fig. 14b) that later became more dominant (balanced tripole, Fig. 14c) was produced by noninductive charge separation between graupel and small ice particles. The classic tripole charge structure hypothesis (Fig. 14d) of a smaller lower positive charge region does not fit in this case except, perhaps, in the decay stage of the storm. The bottom-heavy charge structure allows initial lightning activity between the main negative and lower positive charge regions while creating enough bias in the potential to produce - CG flashes. Both the model and the observed storm produced IC flashes between the lower two regions, suggesting that sufficient potential bias was not always present or perhaps reflecting the vagaries of lightning propagation. The conclusions are consistent with observation of IC lightning in a lower dipole (e.g., Qie et al. 2005; Wiens et al. 2005) and the variation of time from initiation to return stroke in -CG lighting reported by Coleman et al. (2008). The Coleman et al. (2008) data also support the idea that -CG flashes vary in effect from nearly "pure" CG flash more like low, inverted IC flashes.

Noninductive charge separation alone was found to be sufficient to produce strong charging at higher temperatures. Mansell et al. (2005) found this to be possible with the single-moment microphysics if higher ice concentrations were assumed. The vast majority of ice crystals at higher temperatures were produced by rime splintering or drop shattering, which require at least a two-moment microphysics scheme for adequate prediction. Inductive graupeldroplet charge separation, on the other hand, was found to be less significant because of lower droplet concentrations resulting from low $\mathrm{CCN}$ concentrations, drop coalescence, and collection by larger particles.

Repeated initiation of lightning in a given region indicates active charge separation, at least for low-flash-rate storms. For higher charge separation rates, it might be pos- sible for differential sedimentation to restore the electric field high enough for a subsequent flash, but more likely it would enable access by lightning from a close-by cell. On the other hand, it is also possible that when charging rates are great that discharges will deposit greater charge to achieve similar fractional decreases in electrical energy. When lightning is observed repeatedly in storm regions where little or no riming growth is expected, for example at temperatures $T<-40^{\circ} \mathrm{C}$ where no liquid water should be present, other charging conditions might be considered, such as supersaturation with respect to ice as a sufficient condition for appreciable charge separation (Mitzeva et al. 2006).

\section{Acknowledgments.}

Support was provided by the National Severe Storms Laboratory and grants from the National Science Foundation (ATM-0119398 and ATM-0451639). Funding for this research also was provided under NOAA-Univ. of Oklahoma Cooperative Agreement NA17RJ1227. We thank Dr. Louis Wicker and Dr. Jerry Straka for many useful discussions.

\section{REFERENCES}

Brooks, I. M., C. P. R. Saunders, R. P. Mitzeva, and S. L. Peck, 1997: The effect on thunderstorm charging of the rate of rime accretion by graupel. Atmos. Res., 43, 277295.

Bruning, E. C., W. D. Rust, T. J. Schuur, D. R. MacGorman, P. R. Krehbiel, and W. Rison, 2007: Electrical and polarimetric radar observations of a multicell storm in TELEX. Mon. Wea. Rev., 135, 2525-2544, doi:10.1175/MWR3421.1.

Bryan, G. H., 2005: Spurious convective organization in simulated squall lines owing to moist absolutely unstable layers. Mon. Wea. Rev., 133, 1978-1997.

Coleman, L. M., T. C. Marshall, M. Stolzenburg, T. Hamlin, P. R. Krehbiel, W. Rison, and R. J. Thomas, 2003: Effects of charge and electrostatic potential on lightning propagation. J. Geophys. Res., 108, doi:10.1029/2002JD002718.

Coleman, L. M., M. Stolzenburg, T. C. Marshall, and M. A. Stanley, 2008: Horizontal lightning propagation, preliminary breakdown, and electric potential in New Mexico thunderstorms. J. Geophys. Res., 113, doi:10.1029/2007JD009459.

Coniglio, M. C., D. J. Stensrud, and L. J. Wicker, 2006: Effects of upper-level shear on the structure and main- 
tenance of strong quasi-linear mesoscale convective systems. J. Atmos. Sci., 63, 1231-1252.

Deardorff, J. W., 1980: Stratocumulus-capped mixed layers derived from a three-dimensional model. Bound.Layer Meteor., 18, 495-527.

Dwyer, J. R., 2003: A fundamental limit on electric fields in air. Geophys. Res. Lett., 30, doi:10.1029/2003GL017781.

Gish, O. H., 1944: Evaluation and interpretation of the columnar resistance of the atmosphere. Terr. Magn. Atmos. Electr., 49, 159-168.

Helsdon, J. H., Jr. and R. D. Farley, 1987: A numerical modeling study of a Montana thunderstorm: 2. Model results versus observations involving electrical aspects. J. Geophys. Res., 92, 5661-5675.

Helsdon, J. H., Jr., G. Wu, and R. D. Farley, 1992: An intracloud lightning parameterization scheme for a storm electrification model. J. Geophys. Res., 97, 5865-5884.

Jiang, G.-S. and C.-W. Shu, 1996: Efficient implementation of weighted ENO schemes. J. Comp. Phys., 126, $202-228$.

Kato, T., 1995: A box-Lagrangian rain-drop scheme. J. Met. Soc. Japan, 73, 241-245.

Klemp, J. B. and R. B. Wilhelmson, 1978: The simulations of three-dimensional convective storm dynamics. J. Atmos. Sci., 35, 1070-1096.

Leonard, B. P., 1991: The ULTIMATE conservative difference scheme applied to unsteady one-dimensional advection. Comput. Methods Appl. Mech. Eng., 88, 17-74.

MacGorman, D. R., A. A. Few, and T. L. Teer, 1981: Layered lightning activity. J. Geophys. Res., 86, 9900-9910.

MacGorman, D. R., W. D. Rust, T. J. Schuur, M. I. Biggerstaff, J. M. Straka, C. L. Ziegler, E. R. Mansell, E. C. Bruning, K. M. Kuhlman, N. R. Lund, N. S. Biermann, C. Payne, L. D. Carey, P. R. Krehbiel, W. Rison, K. B. Eack, and W. H. Beasley, 2008: TELEX: The thunderstorm electrification and lightning experiment. Bull. Amer. Meteor. Soc., 89, 997-1018.

MacGorman, D. R., J. M. Straka, and C. L. Ziegler, 2001: A lightning parameterization for numerical cloud models. J. Appl. Meteor., 40, 459-478.

Mansell, E. R., D. R. MacGorman, C. L. Ziegler, and J. M. Straka, 2002: Simulated three-dimensional branched lightning in a numerical thunderstorm model. J. Geophys. Res., 107, doi:10.1029/2000JD000244.
- 2005: Charge structure and lightning sensitivity in a simulated multicell thunderstorm. J. Geophys. Res., 110, doi:10.1029/2004JD005287.

Mazur, V., 2002: Physical processes during the development of lightning. C. R. Physique, 3, 1393-1409, doi:10.1029/2001GL014159.

Mazur, V. and L. H. Ruhnke, 1998: Model of electric charges in thunderstorms and associated lightning. $J$. Geophys. Res., 103, 23299-23308.

Mitzeva, R. P., C. P. R. Saunders, and B. Tsenova, 2006: Parameterisation of non-inductive charging in thunderstorm regions free of cloud droplets. Atmos. Res., 82, 102-111, doi:10.1016/j.atmosres.2005.12.006.

Qie, X., T. Zhang, C. Chen, G. Zhang, T. Zhang, and W. Wei, 2005: The lower positive charge center and its effect on lightning discharges on the tibetan plateau. Geophys. Res. Lett., 32, doi:10.1029/2004GL022162.

Riousset, J. A., V. P. Pasko, P. R. Krehbiel, R. J. Thomas, and W. Rison, 2007: Three-dimensional fractal modeling of intracloud lightning discharge in a New Mexico thunderstorm and comparison with lightning mapping observations. J. Geophys. Res., 112, doi:10.1029/2006JD007621.

Saunders, C. P. R., W. D. Keith, and R. P. Mitzeva, 1991: The effect of liquid water on thunderstorm charging. $J$. Geophys. Res., 96, 11007-11017.

Saunders, C. P. R. and S. L. Peck, 1998: Laboratory studies of the influence of the rime accretion rate on charge transfer during crystal/graupel collisions. J. Geophys. Res., 103, 13949-13956.

Shu, C.-W., 2003: High-order finite difference and finite volume WENO schemes and discontinuous Galerkin methods for CFD. Int. J. Comp. Fluid Dyn., 17, 107118.

Wicker, L. J. and W. C. Skamarock, 2002: Time-splitting methods for elastic models using forward time schemes. Mon. Wea. Rev., 130, 2088-2097.

Wicker, L. J. and R. B. Wilhelmson, 1995: Simulation and analaysis of tornado development and decay within a three-dimensional supercell thunderstorm. J. Atmos. Sci., 52, 2675-2703.

Wiens, K. C., S. A. Rutledge, and S. A. Tessendorf, 2005: The 29 June 2000 supercell observed during STEPS. Part II: Lightning and charge structure. J. Atmos. Sci., 62, 4151-4177.

Xue, M., 2000: High-order monotonic numerical diffusion and smoothing. Mon. Wea. Rev., 2853-2864. 
Ziegler, C. L., 1985: Retrieval of thermal and microphysical variables in observed convective storms. Part I: Model development and preliminary testing. J. Atmos. Sci., 42, 1487-1509.

Ziegler, C. L. and D. R. MacGorman, 1994: Observed lightning morphology relative to modeled space charge and electric field distributions in a tornadic storm. J. Atmos. Sci., 51, 833-851.

Ziegler, C. L., D. R. MacGorman, J. E. Dye, and P. S. Ray, 1991: A model evaluation of non-inductive graupelice charging in the early electrification of a mountain thunderstorm. J. Geophys. Res., 96, 12833-12855.

Ziegler, C. L., P. S. Ray, and D. R. MacGorman, 1986: Relations of kinematics, microphysics and electrification in an isolated mountain thunderstorm. J. Atmos. Sci., 43, 2098-2114. 